\section{Os significados e sentidos do plano de parto para as mulheres que participaram da Exposição Sentidos do Nascer}

\author{
Meanings of the childbirth plan for women that \\ participated in the Meanings of Childbirth Exhibit
}

\section{Los significados y sentidos del plan de parto para las mujeres que participaron en la Exposición Sentidos de Nacer}

Fernanda Soares de Resende Santos 1

Paloma Andrioni de Souza 1

Sônia Lansky 1,2

Bernardo Jefferson de Oliveira 1

Fernanda Penido Matozinhos 1

Ana Luiza Nunes Abreu 1

Kleyde Ventura de Souza 1

Érica Dumont Pena 1

doi: $10.1590 / 0102-311 \times 00143718$

\section{Correspondência}

E.D. Pena

Escola de Enfermagem, Universidade Federal de Minas Gerais. Av. Alfredo Balena 190, Belo Horizonte, MG 30130-100, Brasil. ericadumont@gmail.com

parto sobre a experiência de parto, os significados do plano de parto, seus elementos constituintes e a relação do plano de parto com o trabalho de parto e parto. Um estudo descritivo qualitativo foi realizado. Os dados foram coletados por meio do questionário Sentidos do Nascer - Contatos Pós-parto, aplicado via contato telefônico. Incluiu mulheres de Belo Horizonte, Minas Gerais, Brasil, e região metropolitana que participaram da Exposição Sentidos do Nascer, no período de maio a junho de 2015 e março de 2016, quando estavam grávidas, com data do parto anterior ocorrida há mais de um ano e não ter tido abortamento. O tratamento analítico empregado foi a análise de conteúdo das questões. A partir da análise dos dados, emergiram as seguintes categorias referentes ao plano de parto: "presença de acompanhante", "informações sobre os procedimentos", "uso de métodos de alivio de dor", "o uso de anestesia para a continuação do parto normal", "alimentação durante o trabalho de parto", "presença da doula", "não haver intervenção desnecessária", "realização do parto normal", "corte do cordão umbilical após cessar pulsação", "presença e amamentação de recém-nascido pós-parto" e "respeito/tratamento". Observou-se relação direta com a realização do plano de parto e a experiência do parto positiva. Destaca-se a importância da utilização do plano de parto como uma tecnologia que favorece a experiência positiva do parto. A construção do plano pelas mulheres durante o pré-natal e a realização dele por parte da equipe de saúde contribuíram para o desenvolvimento favorável do trabalho de parto.

Parto Humanizado; Tocologia; Percepção
1 Universidade Federal de Minas Gerais, Belo Horizonte, Brasil. 2 Secretaria Municipal de Saúde de Belo Horizonte, Belo Horizonte, Brasil. 


\section{Introdução}

A noção de humanização vem sendo utilizada há vários anos, em especial, na área da saúde, sendo relacionada à humanização da assistência. No campo da assistência ao parto, as discussões sobre a humanização protagonizadas por universidades, organizações não-governamentais e ativistas têm como síntese de suas preocupações a medicalização excessiva do parto 1,2,3.

No avanço da medicalização, destaca-se a institucionalização do parto no ambiente hospitalar. Até meados do século XIX, gravidez e parto eram acontecimentos da esfera privada, partilhados por mulheres no espaço doméstico. A medicalização do parto e da gestação transformou tais eventos em objetos do conhecimento e da prática médica 4,5,6,7,8. Ou seja, em pouco mais de um século, o parto deixou de ser uma experiência da esfera familiar e íntima, compartilhada entre mulheres, para se tornar uma prática dominada pela medicina, institucionalizada nos hospitais e regulada por políticas públicas 9 .

Nesse contexto, o modelo de humanização do parto questiona o uso inapropriado das tecnologias nos hospitais, com destaque para a cesariana que, quando utilizada sem indicação, não apresenta benefícios e ainda pode resultar em complicações, como, por exemplo, as hemorragias, as quais amplificam a morbimortalidade das mulheres. O conceito de humanização é amplo, polissêmico e envolve os conhecimentos, as práticas e as atitudes que objetivam promover a autonomia e o protagonismo das mulheres, de modo a evitar intervenções desnecessárias e a garantir cuidados comprovadamente benéficos capazes de evitar e prevenir a morbimortalidade materna e fetal 4,5,6,7.

Com o propósito de garantir e incentivar o processo de humanização do nascimento nas maternidades brasileiras, os órgãos responsáveis têm publicado, nos últimos anos, diversas portarias e manuais de orientação 10,11,12,13, nos quais, o parto é resgatado como um evento fisiológico e afetivo. Nesse sentido, preconiza-se que a mulher possa ter, caso queira, um acompanhante de sua escolha em todo o processo do pré-parto, parto e puerpério; tenha liberdade de movimentação; possa receber métodos não farmacológicos para alívio da dor; tenha privacidade e a presença constante de um/uma profissional capacitado/a para acompanhar o parto; escolha sobre a posição que deseja parir; que seja ela a primeira a ver seu bebê e a pegá-lo; e ainda que tenha seu medo e sua dor percebidos como legítimos e integrantes do processo 9.

Tais medidas podem e precisam ser escolhidas pela mulher antes e durante o parto, por meio da realização do plano de parto. O plano de parto é um documento, de caráter legal, escrito pelas mulheres grávidas após receberem informações sobre a gravidez e o processo de parto, considerando seus valores e desejos pessoais, além das expectativas criadas sobre seu parto ao longo da gravidez. O plano de parto é o eixo da relação clínica estabelecida entre as mulheres grávidas e o/a profissional e pode servir para orientar a atenção de saúde prestada ao longo de todo o processo 14

O primeiro modelo de plano de parto foi elaborado por Sheila Kitzinger, em 1980, nos Estados Unidos, e defendia que o parto é um processo fisiológico que grande parte das mulheres passaria ao longo de suas vidas e que não pode ser encarado como patológico e medicalizado, como tinha acontecido ao longo dos anos devido à inclusão do parto no ambiente hospitalar. Com a intenção de proporcionar maior autonomia às mulheres e reduzir intervenções desnecessárias, os países anglosaxônicos começaram a utilizar o plano de parto 9 .

A Organização Mundial da Saúde (OMS), desde 1996, recomenda a elaboração do plano de parto e o compreende como mecanismo de incentivo às mulheres pela busca por informações qualificadas, instrumento para a construção das expectativas e dos desejos com relação à experiência da maternidade e um exercício de protagonismo. No rol de recomendações da OMS, presente no guia prático da OMS para o cuidado ao parto normal, o plano de parto se enquadra como categoria A: Práticas que são Demonstradamente Úteis e Devem ser Encorajadas 13.

A importância do plano de parto relaciona-se ainda ao princípio bioético de autonomia, uma vez que propicia o aumento do controle das mulheres sobre o processo do parto, já que se constitui como ferramenta para a preparação para o parto capaz de diminuir os medos das mulheres com base na informação e comunicação proporcionadas, constituindo um processo de reflexão para as mulheres, o que contribui para a produção de um efeito positivo sobre a satisfação 14

Por meio da construção do plano de parto, as mulheres podem fortalecer a confiança em relação ao parto, expressar suas preferências e melhorar a comunicação com a equipe profissional, além de ser 
um método de prevenção quaternária frente à violência obstétrica e de reafirmação de seus direitos sexuais/reprodutivos e acesso à assistência de qualidade. O plano de parto possui também a função de reconduzir o lugar de fala às mulheres parturientes, é importante que o direito das mulheres à sua elaboração seja respeitado pelos/as profissionais que as assistem 14,15,16,17.

Há apontamentos recentes de que, quanto maior o cumprimento do plano de parto, melhores são os resultados relacionados à saúde materna e neonatal 18. Contudo, apesar de as mudanças em relação ao parto e ao nascimento estarem em pauta desde o fim do século passado, e de o plano de parto ser recomendado pela OMS, o seu uso nos países de baixa e média renda ainda é frágil se comparado aos países de alta renda 14 .

Dado o exposto, o estudo visa analisar significados e sentidos do plano de parto para as mulheres que o realizaram. Como objetivos específicos, buscamos compreender os elementos constituintes do plano de parto e a relação do plano de parto com o trabalho de parto e parto. A identificação desses significados e sentidos pode auxiliar profissionais e gestores/as a compreenderem a importância do plano de parto e a procederem à implementação de ações e políticas públicas que auxiliem na sua execução. Tal movimento pode contribuir para a realização de um parto mais humanizado e significativo tanto para as mulheres gestantes quanto para os bebês.

\section{Método}

Trata-se de um estudo qualitativo, realizado por meio de um questionário semiestruturado, aplicado via contato telefônico. Foram contatadas mulheres que haviam participado da Exposição Sentidos do Nascer, no período de maio a junho de 2015 e março de 2016.

O projeto de pesquisa e extensão Sentidos do Nascer conjuga arte, ciência e tecnologia por meio de uma exposição itinerante e interativa sobre o parto e o nascimento. Esse utiliza metodologias de pesquisa-ação para promover transformações nas representações sociais sobre o parto e o nascimento, de modo a criticar o cenário da hipermedicalização do parto, da perda do protagonismo das mulheres e da exploração mercadológica do parto. O projeto conta com financiamento misto, com capital proveniente de recursos públicos e privados 1.

Este artigo analisa narrativas presentes em um dos instrumentos da pesquisa Sentidos do Nascer, o questionário semiestruturado intitulado Sentidos do Nascer - Contatos Pós-parto, composto por 68 perguntas sobre o parto e o pós-parto, além dos dados de identificação da participante e um espaço para observações do(a) entrevistador(a), as quais visam ampliar a compreensão do parto e nascimento vivenciados pelas mulheres que participaram da exposição quando ainda estavam grávidas.

Para compreensão dos significados e sentidos do plano de parto, foram selecionadas as perguntas que possibilitassem uma descrição da experiência a partir da narrativa das mulheres, sendo essas a pergunta 12, a pergunta 3.4 e a pergunta 7 , a saber: " 12 . Conte-nos como foi a sua experiência de parto" e a "3.4. Por favor, comente" referente à pergunta"3.3. Se você fez plano de parto, você considera que a assistência recebida correspondeu ao seu plano de parto?" e a questão "7. Se cesariana, qual foi o motivo?".

Os critérios de inclusão deste estudo foram: mulheres moradoras de Belo Horizonte, Minas Gerais, Brasil, e região metropolitana que participaram da Exposição Sentidos do Nascer, de maio a junho de 2015 e março de 2016, quando estavam grávidas, com data do parto anterior há um ano e não ter tido abortamento. A análise realizada neste estudo inclui apenas as mulheres que relataram terem tido seu plano de parto realizado e os elementos elencados como importantes por elas. Os critérios de exclusão foram: não ser moradora de Belo Horizonte e região metropolitana, não estar grávida no período da exposição, estar grávida durante o contato telefônico, ter tido um abortamento após a visita à exposição e data do parto maior que um ano anterior à pesquisa.

Para este estudo, foram selecionadas as perguntas que possibilitassem uma descrição da experiência a partir da percepção das mulheres, sendo essas: "12. Conte-nos como foi a sua experiência de parto", por abordar, de forma ampla, os sentidos e significados sobre o contexto de parto. Na ausência de informações que respondessem ao nosso objetivo, foram analisadas também as seguintes questões: "3.4. Por favor, comente" referente à pergunta "3.3. Se você fez plano de parto, você considera que a assistência recebida correspondeu ao seu plano de parto?" e a questão "7. Se cesariana, qual foi o motivo?". 
A análise baseou-se na compreensão dos sentidos a partir do núcleo de significados, da metodologia fundamentada na epistemologia da perspectiva sócio-histórica, que enfatiza a compreensão das relações sociais simultaneamente à individualidade das ações do sujeito, possibilitando compreender a abrangência e a subjetividade dos diversos comportamentos, sua historicidade e dialética. Dessa forma, analisou-se as particularidades das mulheres, por meio dos significados atribuídos por elas ao período perinatal, compreendendo que esses significados são constituídos da materialidade histórica dos sujeitos, suas subjetividades e aspectos da cognição presentes na sua realidade 19 .

Buscou-se analisar os trechos de fala articulados que constituem um significado a partir da análise temática. Tendo como base a compreensão de que as mensagens textuais produzem temáticas, foi possível dividir os relatos em temas principais articulados ao tema central. Foram considerados temas-significantes realizando-se pré-análise a partir da leitura sintagmática de pensamento, seguindo o encadeamento único e realizado numa entrevista, que se manifesta por uma sucessão de palavras, frases e sequências e, ao mesmo tempo, paradigmática tendo, em mente, o universo de possíveis: isto não foi dito, mas podia tê-lo sido, ou foi efetivamente dito noutra entrevista 20 .

Os primeiros temas-significantes estão destacados na Figura 1. Em seguida, o material foi explorado, enfatizando-se o plano de parto, sendo esse dividido em três categorias (Figura 2).

Após analisar o que desencadeou (ou não) o seguimento do plano de parto, por meio dos relatos de sentimentos e experiências dessas mulheres, foi possível subcategorizar os resultados a partir de elementos elencados como importantes por elas. A análise realizada neste estudo inclui apenas as mulheres que relataram terem tido seu plano de parto realizado e os elementos elencados como importantes por elas.

O estudo seguiu as determinações da Resolução no 466/2012, que regulamenta as normas de pesquisa envolvendo seres humanos. Obteve autorização para seu desenvolvimento no Comitê de Ética em

\section{Figura 1}

Categorização de experiências.

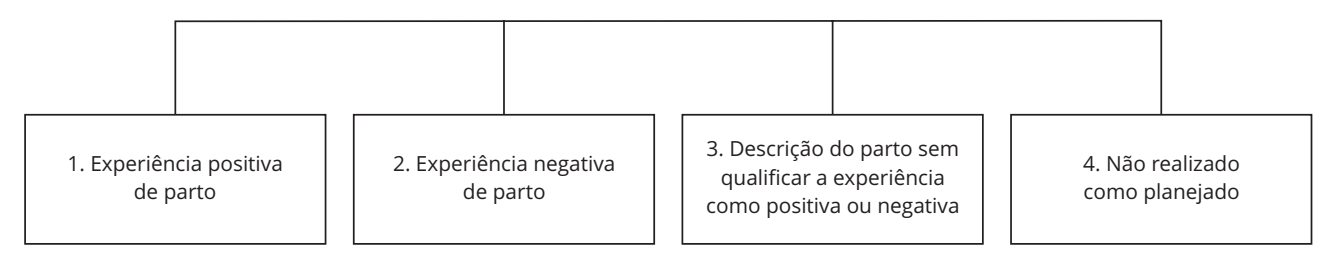

Figura 2

Plano de parto.

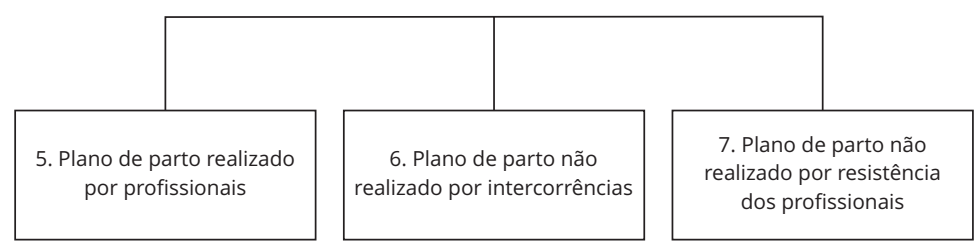


Pesquisa (CEPAS) da Universidade Federal de Minas Gerais (UFMG), sob o parecer número 31/2008. O estudo ainda segue as determinações da Resolução no 510/2016, que regulamenta o respeito pela dignidade humana e pela especial proteção devida aos participantes das pesquisas científicas envolvendo seres humanos. A identificação dos participantes foi efetuada por meio de numeração da pesquisa, de forma a assegurar o anonimato.

\section{Resultados e discussão}

\section{Caracterização das participantes}

Foram contatadas 781 mulheres, dessas, 415 responderam ao questionário pós-parto, três sofreram abortamento, três optaram por não participar, e 360 não responderam ao questionário. Das 415 mulheres, $60 \%(\mathrm{n}=249)$ relataram ter realizado o plao de parto durante a gravidez, sendo que $57,6 \%$ $(n=234)$ delas descreveram essa experiência nas perguntas selecionadas para o presente estudo.

Das mulheres que realizaram o plano de parto, identificou-se que 54,6\% ( $n=136)$ tiveram partos em hospital/maternidade particular; 33,7\% ( $\mathrm{n}=84)$, em maternidade do Sistema Único de Saúde (SUS); 6,8\% ( $\mathrm{n}=17)$, em domicílio; 4,4\% ( $\mathrm{n}=11)$, em centro de parto normal; e $0,4 \%(\mathrm{n}=1)$ não relatou o local de parto.

A via de nascimento de maior ocorrência foi vaginal, representando $61 \%(\mathrm{n}=152)$. Cinco mulheres relataram partos com uso de fórceps/vácuo extrator; e 37\% $(\mathrm{n}=92)$, cesarianas. Dessas, $56,5 \%$ $(n=52)$ realizaram a cirurgia antes do início do trabalho de parto, e outras $43,5 \%(n=40)$ entraram em trabalho de parto.

De acordo com a primeira classificação dos relatos de experiências, 55\% das mulheres realizaram o plano de parto e consideraram que tiveram ótimas e boas experiências ( $\mathrm{n}=137) ; 14 \%$, que o plano de parto não foi realizado como planejado $(\mathrm{n}=35)$; $12 \%$ descreveram o parto sem qualificar a experiência como positiva ou negativa $(n=30) ; 11 \%$, como experiência negativa $(n=27)$; e $8 \%$ não responderam à questão $(\mathrm{n}=20)$.

A partir dos relatos, foi possível categorizar e observar que, das 234 mulheres que descreveram suas experiências, $65 \%$ obtiveram o plano de parto praticado ( $\mathrm{n}=152$ ), em $22,6 \%$, não foi praticado por intercorrências $(\mathrm{n}=53)$, e, em 12,4\%, não foi praticado por resistência dos profissionais $(\mathrm{n}=29)$. Em seguida, observou-se que o plano de parto praticado foi citado três vezes mais se comparado ao plano de parto não praticado por intercorrências e ao plano de parto não praticado por resistência dos profissionais.

\section{O plano de parto na perspectiva das mulheres}

Na perspectiva delas, o plano de parto reúne elementos que dizem respeito aos direitos garantidos a todas as mulheres, que, mesmo sendo práticas recomendadas pela OMS, apoiadas pelo Ministério da Saúde 11,13, claramente úteis e que devem ser incentivadas, muitas vezes, ainda permanecem negligenciadas, como: "presença de acompanhante", "informações sobre os procedimentos", "não haver intervenção desnecessária”, "uso de métodos de alívio de dor", “corte do cordão umbilical após cessar pulsação", "presença e amamentação de recém-nascido pós-parto”. Esses direitos negligenciados, sobretudo às mulheres negras e pobres 21,22 , descortinam as violências obstétricas, muitas vezes, invisibilizadas no cotidiano da assistência ao parto e nascimento.

Por meio da utilização desse documento, as mulheres podem expor seus anseios, expectativas e necessidades, tornando-se protagonistas do cuidado no momento do parto. O empoderamento feminino contribuirá para o poder de decisão e a defesa dos seus direitos durante o pré-natal, trabalho de parto e nascimento 23 .

Todas as mulheres têm direito ao mais alto padrão de saúde atingível, incluindo o direito a uma assistência digna e respeitosa durante toda a gravidez e o parto, assim como o direito de estar livre da violência e discriminação de serem iguais em dignidade, de serem livres para procurar, receber e dar informações e de usufruírem do mais alto padrão de saúde física e mental, incluindo a saúde sexual e reprodutiva 24 . 
O plano de parto significa, para muitas mulheres do estudo, "respeito/tratamento", que abrange mais do que aceitar e acatar suas escolhas, envolve o cuidado e o saber científico, a gentileza, a forma como é oferecido o apoio, transmitindo segurança e conforto e promovendo o bem-estar. As mulheres referiram o respeito como o principal significado para o plano de parto praticado. Os relatos enfatizam a aceitação dos profissionais quanto às suas escolhas, não insistência em escolhas que não fossem as das mulheres e ao tratamento dos profissionais no momento do parto de forma respeitosa, atenciosa e com os cuidados direcionados a elas.

“...Foi uma relação de bastante respeito e confiança, me senti muito à vontade...” (Relato 194).

"O meu parto foi super respeitoso, eu fiquei de oito a dez horas em trabalho de parto, e a gente foi até onde meu corpo dava conta. (...), mas foi tudo respeitoso e do meu jeito” (Relato 30).

As mulheres que recebem apoio contínuo durante o parto apresentam maior probabilidade de ter um parto vaginal espontâneo e menos prolongado; menor probabilidade de serem submetidas à analgesia intraparto/anestesia, ao parto vaginal instrumental ou à cesariana; e de ter um bebê com baixo índice de Apgar no quinto minuto de vida 25,26. A presença de acompanhante, durante o trabalho de parto e parto, foi relatada como positiva, fornecendo à gestante a sensação de segurança durante um momento de fragilidade emocional e de dor. A presença do acompanhante teve como finalidade encorajar e apoiar, verbalmente ou gestualmente, as mulheres de forma a garantir boa evolução do parto.

“...Então assim (...) pra mim foi muito bom, superou minhas expectativas. Foi muito importante meu marido na hora da dor, ele me ajudava a controlar, ele foi muito importante, quando eu saía do foco e ele me puxava e me lembrava do que eu queria....

Reconhecendo o papel fundamental da doula na atenção às mulheres durante a evolução do trabalho de parto, essa presta constante apoio emocional por meio de atitudes, como: segurar a mão das mulheres, trabalhar técnicas de respiração, encorajar e tranquilizar. O acompanhamento por doulas contribui para a redução do tempo em trabalho de parto, bem como do uso de analgésicos e fórceps e da realização de cesarianas. Além disso, parturientes que foram acompanhadas por doulas apresentaram-se em maior frequência amamentando, com mais autoestima, menos depressão e maior interação com seus filhos 10. Assim como a presença do acompanhante transmitiu segurança às mulheres, a presença das doulas, no trabalho de parto e parto, foi relatada como importante.

“...Tive acompanhamento de uma doula e acredito que é fundamental principalmente em não optar pela analgesia...” (Relato 322).

"Eu tive um acompanhamento ao longo da gestação com uma doula, então isso me deu uma sensação de segurança. Isso me fez enfrentar tudo com mais segurança. (...) Quando começou a fase mais intensa, ela ficou comigo até o final. (...) Foi uma relação de bastante respeito e confiança, me senti muito à vontade. (...) No outro dia, a doula veio me ver, me ajudou um pouco e seguiu a vida..." (Relato 194).

Para assegurar a presença do acompanhante de livre escolha das mulheres, é fundamental que ocorra a fiscalização dos órgãos responsáveis nas instituições de saúde vinculadas ao SUS ou à saúde suplementar, bem como mudanças na formação dos profissionais para a assistência ao parto.

É necessário que o/a profissional de saúde ouça a paciente cuidadosamente e forneça explicações de modo que a paciente possa entender, dispondo de tempo suficiente para esclarecer todas as suas dúvidas. Deve dizer de forma clara, objetiva e compreensível. Informar sobre as opções, alternativas e permissão para tomar decisões sobre o tipo de procedimento ou tratamento, depois de discutir com o/a profissional de saúde, devendo ser encorajada a questionar. Podendo recusar a realização de qualquer intervenção 27.

As informações sobre os procedimentos que poderiam ser utilizados durante o trabalho de parto e parto são citadas como forma de prevenir violência obstétrica e possíveis atitudes tomadas pelos profissionais que não fossem da vontade das mulheres. Durante o trabalho de parto e parto, as mulheres relataram que a informação sobre o que, o porquê e quando seria realizado qualquer procedimento é importante para mantê-las calmas e seguras, além de ser oportunidade de escolha a elas.

"Olha, foi uma experiência muito positiva, porque se eu for fazer uma comparação com meus outros partos, teve coisa que eu não sabia e a exposição me esclareceu o que eu não sabia. Tipo, o médico puxar o bebê, dar ocitocina, e eu vi que não era assim. Foi uma experiência muito gratificante mesmo..." (Relato 110).

“...o tempo todo me perguntaram qual procedimento eu queria, sobre episiotomia, mas eu não quis. O tempo todo me perguntaram, e eu escolhia o procedimento. (...) Experiência muito forte e intensa, dor intensa mas a exposição influenciou a ter uma experiência melhor e enfrentar bem a dor..." (Relato 390). 
O uso dos métodos de alívio de dor não farmacológicos apresenta resultados positivos em relação à diminuição da dor, à menor necessidade de analgesia, ao controle da ansiedade e do estresse, além de proporcionar percepção positiva e sensação de controle pelas mulheres ${ }^{28}$. As mulheres do estudo relatam que os métodos foram ofertados principalmente pelos profissionais de enfermagem e as doulas, a fim de relaxar e controlar a dor. Auxiliou na participação ativa das mulheres, o que gerou sensação de autonomia, capacidade de prosseguir com o parto, além de ter auxiliado na garantia de que os desejos das mulheres fossem respeitados naquele momento.

“...Fui pro chuveiro, sentada na bola de pilates, para aliviar. Funcionou muito bem. (...) Na sala, variei de posições, ora sentada no sofá, ora sentada na bola, tentava mexer, mas a dor não tava fácil. Recebi minha tão sonhada massagem para aliviar dores. Passei a gestação sonhando com massagem, mas nem lembro direito mais. Risos. (...) Foi quando fui para a banheira. (...) A banheira ajudou a descansar entre as contrações e ganhar mais um fôlego. (...) Como não conseguia mudar de posição durante a contração, optei em ficar de cócoras direto que é uma posição confortável para mim".

“...Fiquei no chuveiro, na cama deitada, de cócoras (...) da maneira que me sentia melhor. E a enfermeira ia me falando como possivelmente ia ficar melhor..." (Relato 378).

Para as mulheres que estão na fase inicial do trabalho de parto e desejam comer, o jejum obrigatório pode causar uma progressão insatisfatória, recaindo na cascata de intervenções que culminam em uma cesariana. Durante o processo de parturição, o dispêndio de energia é o equivalente ao exercício físico moderado contínuo e, no caso do trabalho de parto prolongado associado ao jejum, há o aumento progressivo de cetonas urinárias. A preocupação excessiva dos profissionais com a restrição alimentar deve-se ao risco de aspiração do conteúdo gástrico, caso a parturiente venha a regurgitar durante um procedimento anestésico; porém, evidências apontam que o risco de aspiração está diretamente associado ao uso de anestesia geral no parto, que, atualmente, é muito baixo, além dos cuidados do(a) profissional que administra a anestesia 29.

A alimentação durante o parto traz às mulheres melhores condições físicas para o momento expulsivo, além de não causar nenhum transtorno durante o parto 28. Algumas mulheres receberam alimentação durante o parto, o que fez com que elas, segundo relato, sentissem-se acolhidas e à vontade no ambiente.

“...pude comer durante o trabalho de parto..." (Relato 110).

"...Como eu queria o parto natural, eu fui muito aberta a receber massagem, o chuveiro também, eu pude me alimentar nos intervalos das contrações, eu pude ter esse momento de passar pelo processo da contração de forma muito tranquila..." (Relato 179).

“...Fiquei bem à vontade, pude comer até meu limite..." (Relato 255).

A analgesia epidural ofereceu um melhor alívio da dor no trabalho de parto. No entanto, as mulheres que usam essa forma de alívio da dor têm um risco aumentado de parto instrumental quando comparadas com mulheres que usam técnicas não epidurais, formas de analgesia ou nenhuma analgesia 27. Não há estatisticamente evidência significativa de diferença na satisfação materna com o alívio da dor, o risco de cesariana, dor nas costas a longo prazo ou efeitos adversos imediatos no recém-nascido 30.

$\mathrm{O}$ uso da anestesia foi visto por essas mulheres como auxílio para que pudessem continuar o trabalho de parto, já que muitas relataram que estavam cansadas, quase desistindo de realizar parto normal no momento em que receberam a anestesia. Após receberem a anestesia, relatam alívio da dor e melhor evolução do parto

"A analgesia foi dada quando eu estava por volta dos $8 \mathrm{~cm}$. Foi ótimo! Senti um alivio tremendo e pude continuar tranquilamente meu trabalho de parto..." (Relato 103).

“...A anestesia aliviou a dor e me senti renovada. Falei que faria o que eles quisessem..." (Relato 379).

As mulheres relataram ter preferência pelo parto por via vaginal no plano de parto. É possível que, por um lado, a dor do parto seja concebida como algo inerente ao processo de parturição e, por outro, que seja considerada como parte da experiência de se tornar mãe, já que a capacidade de enfrentar ou resistir ao trabalho de parto e parto seria um dos aspectos valorizados da passagem para o status de adulta e mãe, representada pela parturição para mulheres de camadas populares urbanas 31. Após conseguirem concretizar o desejo do parto normal, as mulheres do estudo expressam contentamento por sentirem-se fortalecidas ao gerarem os seus filhos, por sentirem as dores do parto e por criarem vínculo mãe-filho desde o momento do nascimento. 
"Tive um parto que tenho muito orgulho de ter tido. Vivenciei como um parto natural é benéfico para mãe e bebê. Minha recuperação foi excelente e a minha filha nasceu super forte e saudável. (...) Sinto-me ainda mais encorajada e forte por ter conseguido o parto natural, por ter sentido tudo de forma natural sem intervenções. (...) Deixar ser dominada pelos instintos e sentimentos do trabalho de parto foi a experiência mais sublime e diferente que já vivi na vida. Foi o descontrole que mais me fez bem na vida e tenho certeza que também trouxe muitas coisas boas para a minha filha (...)" (Relato 406).

Intervenções ainda são realizadas durante o trabalho de parto, mesmo não havendo evidências científicas que comprovem sua efetividade. Muitas são deletérias e precisam ser desestimuladas por causarem danos psicológicos e físicos, como o aumento da ansiedade, da dor, os danos ao útero, períneo e feto 32 . Igualmente ao sentimento das mulheres ao terem realizado parto por via vaginal, algumas citam orgulhosas por não terem sofrido nenhuma intervenção.

"Meu parto foi natural, sem uso de qualquer intervenção. Tive um parto natural após uma cesárea dentro de um hospital particular. (...) Não houve anestesia, não houve epsio, não utilizei soro. Ninguém do hospital encostou em mim ou interferiu..." (Relato 345).

O corte do cordão umbilical tardio (um a três minutos) após o nascimento do recém-nascido é recomendado pela OMS para prevenção e tratamento de hemorragia pós-parto, o atraso no clampeamento do cordão umbilical permite que o sangue continue a passar da placenta ao neonato após o parto. Considera-se que esse pequeno atraso aumenta as reservas de ferro em mais de $50 \%$ aos 6 meses de idade entre recém-nascidos a termo. Além de diminuir o risco de hemorragia, dimunui as chances de enterocolite e septicemia em bebês 33 .

O corte do cordão umbilical após cessar de pulsar foi solicitado por algumas mulheres. Pelos relatos, foi possível perceber que, nesse momento, é desejo das mulheres e do companheiro que ele tenha a oportunidade de participar ativamente do parto.

“...Eu queria que meu marido cortasse o cordão umbilical, aí o médico do hospital foi meio resistente com isso, mas aí minha médica disse que não tinha problema. Quando o cordão tava quase parando de pulsar, meu marido foi lá e cortou. Então, assim (...) pra mim foi uma experiência incrivel” (Relato 179).

“...Esperamos o cordão parar de pulsar para poder cortar. Tem até uma foto com o José em cima da cama com o cordão em forma de coração ligado nele e na placenta. Foi uma experiência incrível” (Relato 293).

O contato precoce pele a pele proporciona benefícios imediatos e em longo prazo, uma vez que melhora a efetividade da primeira mamada, regula a temperatura corporal do bebê e contribui para a vinculação materna 14 . A amamentação e a presença do recém-nascido pós-parto foram reconhecidas como um momento importante para a criança e para as mulheres.

“...Fui internada 8 da manhã e ela nasceu 11:29 (...) linda, foi pro meu colo, mamou no primeiro segundo de vida e ficamos todas muito bem!!!” (Relato 186).

“...Eu que peguei ele, amparei ele. Foi lindo, depois quem pegou ele foi meu marido, depois de algumas horas que ele saiu do contato da gente. O primeiro olhar dele foi pra mim e o meu pra ele e depois pro meu marido, eu vou querer mais o que né?..." (Relato 277).

\section{Conclusão}

Em sua maioria, as mulheres que realizaram o plano de parto relataram experiências positivas durante o trabalho de parto, parto e pós-parto. Destacam-se o "respeito e tratamento", "uso de métodos de alívio de dor" e a "presença de acompanhante", práticas diretamente relacionadas ao conhecimento das mulheres e as práticas dos profissionais com influência direta no trabalho de parto e parto, assim como na satisfação das mulheres.

Os elementos apresentados no plano de parto trazem significado para as mulheres em relação a seus direitos, anseios e sua participação ativa do seu próprio cuidado no momento do parto. Esses aspectos propiciam, a ela, uma experiência agradável, fisiológica, menos dolorosa, reforçando sua autonomia quanto ao planejamento e à execução do próprio parto.

Consideramos que os resultados corroboram com a literatura vigente a respeito do tema e asseguram uma perspectiva de cuidado integral, o que contribui para educação permanente dos profissionais e ações de educação perinatal. O plano de parto mostra-se, portanto, um fundamental instrumen- 
to potencializador da autonomia das mulheres e das famílias, incentivo ao cuidado compartilhado e exercício de reflexão acerca da realidade obstétrica.

Apresenta-se como possível limitação do estudo a impossibilidade de análise dos dados de 360 participantes (quase metade) por não terem respondido ao questionário. Pressupõe-se que as implicações desses dados ao estudo não alteram a relevância e abrem possibilidades de novas análises em pesquisas futuras. Optou-se por não analisar o perfil socioeconômico das participantes nem o local e o tipo de parto, correlacionando-os ao plano de parto, pois amplia as delimitações do estudo, não cabendo ao atual objetivo.

Espera-se que este estudo possa contribuir para evidenciar a importância do uso do plano de parto para que as experiências sejam positivas, a fim de melhorar as condições da assistência prestada pela equipe multidisciplinar às mulheres durante a gestação e o parto.

\section{Colaboradores}

F. S. R. Santos e P. A. Souza contribuíram substancialmente na concepção, desenho do trabalho, aquisição, análise e interpretação de dados, elaboração e revisão crítica do conteúdo intelectual. S. Lansky e B. J. Oliveira participaram da elaboração do trabalho e revisão crítica do conteúdo intelectual e na aprovação final da versão a ser publicada. F. P. Matozinhos e A. L. N. Abreu colaborou na elaboração do trabalho e revisão crítica do conteúdo intelectual. K. V. Souza contribuiu na aprovação final da versão a ser publicada. E. D. Pena participou na elaboração do trabalho e revisão crítica do conteúdo intelectual, aprovação final da versão a ser publicada e é responsável por todos os aspectos do trabalho para garantir que as questões relacionadas com a precisão ou a integridade fossem adequadamente investigadas e resolvidas.

\section{Informações adicionais}

ORCID: Fernanda Soares de Resende Santos (0000-0001-5009-7187); Paloma Andrioni de Souza (0000-0002-6051-317X); Sônia Lansky (00000001-5533-4858); Bernardo Jefferson de Oliveira (0000-0002-9528-9147); Fernanda Penido Matozinhos (0000-0003-1368-4248); Ana Luiza Nunes Abreu (0000-0001-6952-1064); Kleyde Ventura de Souza (0000-0002-0971-1701); Érica Dumont Pena (0000-0003-1220-6041).

\section{Agradecimentos}

Ao Conselho Nacional de Desenvolvimento Científico e Tecnológico (CNPq), ao Ministério da Saúde, à Fundação Bill \& Melinda Gates e a todas as mulheres que tornaram este estudo possível.

\section{Referências}

1. Green J, Coupland W, Kitzinger J. Great expectations: a prospective study of women's expectations and experiences of childbirth. Cheshire: Books for Midwives Press; 1998.

2. Rede pela Humanização do Parto e Nascimento. Carta de Campinas. Brasília: Rede pela Humanização do Parto e Nascimento; 1993.

3. Wagner M. Pursuing the birth machine: the search for appropriate birth techonology. Camperdown: ACE Graphics; 1994.

4. Maia MB. Assistência à saúde e ao parto no Brasil. In: Maia MB, organizador. Humanização do parto: política pública, comportamento organizacional e ethos profissional. Rio de Janeiro: Editora Fiocruz; 2010. p. 42-9.

5. Serruya SJ, Lago TG, Cecatti JG. Avaliação preliminar do programa de humanização no pré-natal e nascimento no Brasil. Rev Bras Ginecol Obstet 2004; 26:517-25.

6. Área Técnica de Saúde da Mulher, Secretaria de Políticas de Saúde, Ministério da Saúde. Parto, aborto e puerpério: assistência humanizada à mulher. Brasília: Ministério da Saúde; 2001.

7. Tornquist CS. Paradoxos da humanização em uma maternidade no Brasil. Cad Saúde Pública 2003; 19 Suppl 2:S419-27.

8. Diniz CSG. Humanização da assistência ao parto no Brasil: os muitos sentidos de um movimento. Ciênc Saúde Colet 2005; 10:627-37.

9. Chacham AS, Perpétuo IHO. Determinantes sócio-econômicos da incidência de partos cirúrgicos em Belo Horizonte. In: Anais do X Encontro Nacional de Estudos Populacionais. Belo Horizonte: Associação Brasileira de Estudos Populacionais; 1996. p. 2587-610.

10. Leão VM, Oliveira SMJV. O papel da doula na assistência à parturiente. REME Rev Min Enferm 2006; 10:24-9.

11. Departamento de Gestão e Incorporação de Tecnologias em Saúde, Secretaria de Ciência, Tecnologia e Insumos Estratégicos, Ministério da Saúde. Diretrizes nacionais de assistência ao parto normal: versão resumida. Brasília: Ministério da Saúde; 2017. 
12. Brasil. Portaria no 1.459 , de 24 de junho de 2011. Institui, no âmbito do Sistema Único de Saúde - SUS - a Rede Cegonha. Diário Oficial da União 2011; 27 jun.

13. Organização Mundial da Saúde. Assistência ao parto normal: um guia prático. Genebra: Organização Mundial da Saúde; 2000.

14. Suárez-Cortés M, Armero-Barranco D, Canteras-Jordana M, Martínez-Roche ME. Uso e influencia de los planes de parto y nacimiento en el proceso de parto humanizado. Rev Latinoam Enferm 2015; 23:520-6.

15. Cunha KJB, Gomes LSV, Santos RMA. O vivido de mulheres no parto humanizado. Revista Interdisciplinar NOVAFAPI 2012; 5:32-8.

16. Tesser CD, Knobel R, Andrezzo HFA, Diniz SG. Violência obstétrica e prevenção quaternária: o que é e o que fazer. Rev Bras Med Fam Comunidade 2015; 10:1-12.

17. Gomes RPC, Silva RS, Oliveira DCC, Manzo BF, Guimarães GL, Souza KV. Plano de parto em rodas de conversa: escolhas das mulheres. REME Rev Min Enferm 2017; 21:e1033.

18. Hidalgo-Lopezosa P, Hidalgo-Maestre M, Rodríguez-Borrego MA. Birth plan compliance and its relation to maternal and neonatal outcomes. Rev Latinoam Enferm 2017; 25:e2953.

19. Oliveira CM. Método e sociologia em Weber: alguns conceitos fundamentais. Revista Eletrônica Inter-Legere 2008; (3):1-10.

20. Bardin L. Análise de conteúdo. São Paulo: Edições 70; 2011.

21. Leal MC, Gama SGN, Pereira APE, Pacheco VE, Carmo CN, Santos RV. A cor da dor: iniquidades raciais na atenção pré-natal e ao parto no Brasil. Cad Saúde Pública 2017; 33 Suppl 1:e00078816.

22. d'Orsi E, Brüggemann OM, Diniz CSG, Aguiar JM, Gusman CR, Torres JA, et al. Desigualdades sociais e satisfação das mulheres com o atendimento ao parto no Brasil: estudo nacional de base hospitalar. Cad Saúde Pública 2014; 30 Suppl 1:S154-68.

23. Mouta RJ, Silva TMA, Melo PTS, Lopes NS, Moreira VA. Plano de parto como estratégia de empoderamento feminino. Rev Baiana Enferm 2017; 31:e20275.
24. Organização Mundial da Saúde. Prevenção e eliminação de abusos, desrespeito e maus-tratos durante o parto em instituições de saúde. Genebra: Organização Mundial da Saúde; 2014.

25. Hodnett ED, Gates S, Hofmeyr G, Sakala C. Continuous support for women during childbirth. Cochrane Database Syst Rev 2011; (2):CD003766.

26. Monguilhott JJC, Brüggemann OM, Freitas PF, d'Orsi E. Nascer no Brasil: the presence of a companion favors the use of best practices in delivery care in the South region of Brazil. Rev Saúde Pública 2018; 52:1.

27. Vaitsman J, Andrade GRB. Satisfação e responsividade: formas de medir a qualidade e a humanização da assistência à saúde. Ciênc Saúde Colet 2005; 10:599-613.

28. Gayeski ME, Brüggemann OM. Métodos não farmacológicos para alívio da dor no trabalho de parto: uma revisão sistemática. Texto Contexto Enferm 2010; 19:774-82.

29. Wei CY, Gualda DMR, Santos Junior HPO. Movimentação e dieta durante o trabalho de parto: a percepção de um grupo de puerpéras. Texto Contexto Enferm 2011; 20:717-25.

30. Anim-Somuah M, Smyth RM, Jones L. Epidural versus non-epidural or no analgesia in labour. Cochrane Database Syst Rev 2011; (12):CD000331.

31. Hotimsky SN, Rattner D, Venancio SI, Bógus CM, Miranda MM. O parto como eu vejo... ou como eu o desejo? expectativas de gestantes, usuárias do SUS, acerca do parto e da assistência obstétrica. Cad Saúde Pública 2002; 18:1303-11.

32. d'Orsi E, Chor D, Giffin K, Ângulo-Tuesta A, Barbosa GP, Gama AS, et al. Qualidade da atenção ao parto em maternidades do Rio de Janeiro. Rev Saúde Pública 2005; 39:646-54.

33. Organización Mundial de la Salud. Pinzamiento tardío del cordón umbilical para reducir la anemia en lactantes. Genebra: Organización Mundial de la Salud; 2013. 


\section{Abstract}

This study aimed to analyze the perspective of women who used the childbirth plan on their childbirth experience, the meanings of the childbirth plan and its components, and the relationship between the childbirth plan and labor and delivery. A qualitative descriptive study was performed. Data were collected with the questionnaire Meanings of Birth - Postpartum Contacts, applied via telephone contact. The study included women from the city and greater metropolitan area of Belo Horizonte, Minas Gerais, Brazil, that participated in the Meanings of Childbirth Exhibit in May-June 2015 and March 2016, when they were pregnant, with date of previous childbirth having occurred at least a year previously and without having experienced abortion. The questions were analyzed with content analysis. Data analysis revealed the following categories related to the childbirth plan: "presence of an accompanying person", "information on procedures", "use of pain relief methods", "use of anesthesia to continue with normal delivery", "eating during labor", "presence of a doula", "no unnecessary intervention", "normal delivery", "umbilical cord cut after pulsation", "presence of postpartum breastfeeding", and "respect/treatment". There was a direct relationship between performing the childbirth plan and a positive childbirth experience. This highlights the importance of using the childbirth plan as a technique that favors a positive childbirth experience. Women's development of the plan during prenatal care and its use by the attending healthcare team contributes to favorable labor.

Humanizing Delivery; Midwifery; Perception

\section{Resumen}

El objetivo fue analizar la percepción de las mujeres que participaron en el plan de parto sobre su experiencia durante el mismo, los significados del plan de parto, sus elementos constituyentes y la relación del plan de parto con el trabajo de parto y el parto en sí. Se realizó un estudio descriptivo cualitativo. Los datos se recogieron mediante el cuestionario Sentidos de Nacer - Contactos Posparto, aplicado por contacto telefónico. Incluyó a mujeres de Belo Horizonte, Minas Gerais, Brasil, y región metropolitana que participaron en la Exposición Sentidos de Nacer, durante el período de mayo a junio de 2015 y marzo de 2016, cuando estaban embarazadas, con un parto anterior con fecha de hacía más de un año y no haber sufrido un aborto. El tratamiento analítico empleado fue el análisis de contenido de las cuestiones. A partir del análisis de los datos, surgieron las siguientes categorías referentes al plan de parto: "presencia de acompañante", "información sobre los procedimientos", "uso de métodos para aliviar el dolor", "uso de anestesia para continuar con el parto normal", "alimentación durante el trabajo de parto", "presencia de una partera", "inexistencia de intervención innecesaria", "realización de parto normal", "corte del cordón umbilical tras cesar la pulsación", "presencia y lactancia de recién nacido posparto" y "respeto/tratamiento". Se observó la relación directa con la realización del plan de parto y la experiencia de parto positiva. Se destaca la importancia de la utilización del plan de parto como una tecnología que favorece la experiencia positiva del parto. La construcción del plan por parte de las mujeres durante el período prenatal y la realización del mismo, por parte del equipo de salud, contribuyen al desarrollo favorable del trabajo de parto.

Parto Humanizado; Partería; Percepción

Recebido em 20/Jul/2018

Versão final reapresentada em 27/Dez/2018

Aprovado em 21/Fev/2019 